Editorial

\title{
Sustainability as a Multi-Criteria Concept: New Developments and Applications
}

\author{
Luis Diaz-Balteiro ${ }^{1, *(\mathbb{C})}$, Jacinto González-Pachón ${ }^{2}$ and Carlos Romero ${ }^{1}$ (i) \\ 1 Department of Engineering and Forest and Environmental Management, Universidad Politécnica de Madrid, \\ Etsimfmn 28040 Madrid, Spain; carlos.romero@upm.es \\ 2 Department of Artificial Intelligence, Universidad Politécnica de Madrid, Etsif 28040 Madrid, Spain; \\ jacinto.gonzalez.pachon@upm.es \\ * Correspondence: luis.diaz.balteiro@upm.es
}

Received: 8 September 2020; Accepted: 10 September 2020; Published: 12 September 2020

The sustainable management of the environment and its embedded resources is one of the most important, if not the major challenge of the 21st century, which demands from current science and technology the development of a scientifically sound conceptual framework that is implementable from an operational point of view for properly tackling this important and complex topic. Although important steps have been taken in the right direction, nowadays, this type of theoretical framework is far from being fully achieved or, especially, accepted by the several institutions forming the current democratic societies. In our view, this theoretical framework should be supported by a plurality of scientific theories which implies the convergence of knowledge flowing from many disciplinarian fields like computational sciences, ecology, economics, mathematics, sociology, etc. This convergence of disciplines, plus its necessary social acceptance, makes its setting highly challenging.

To go deeper into the difficulties associated with the above challenge, it might be useful to distinguish between what could be called the "old" and "new" sustainability. To address this task, it makes sense to trace the origins of the idea of sustainability and analyse how this concept has evolved to its current form. In this sense, we should be aware that the idea of sustainability was born at the beginning of the 18th century in the field of forestry by von Carlowitz [1]. This illustrious German nobleman defined a sustainable forest plan as the one which could provide a long-term stable supply of a flow of timber and timber-linked products (e.g., fruits, firewood, etc.) indispensable for the welfare of human beings. In other words, this classic or "old" view of sustainability was conceptualized from a mono-functionality perspective. This approach was similarly applied later on, to other natural resources, and the term gained visibility after its massive implementation in the environmental domain [2]. Within this framework, the necessary and sufficient condition for the sustainable management of a resource is analytically very straightforward: "the use rate must be less than the rate of biological regeneration of the specific resource studied". Maintaining this condition would guarantee the future sustainable management of the resource.

It is important to note that this type of approach implicitly assumes the view that economic systems interact with the environment in a way which, nowadays, could be considered unrealistic. In fact, within this orientation, it is accepted that the environment provides two basic functions for economic activity: first, sources of raw materials to be used as inputs for the different production processes and, second, the assimilation of all the waste generated by those production and consumption processes. Moreover, in this old approach to sustainability, it is implicitly assumed that the environment has a practically infinite capacity to sustain those two basic functions: a source of inputs and a sink for waste. In other words, this view of sustainability has been established within what is called a linear model, linking the environment and the economic systems. 
This theoretical and operational approach has worked well for many years, proving to be very fertile for establishing rational guidelines geared towards an efficient use of the environment and its embedded resources. In the last quarter of the $20^{\text {th }}$ century, this theoretical orientation was well established in the economics field with the publication of several seminal and pioneer textbooks, forming what is known now as the environmental economics discipline.

It is important to insist on the fact that the above conceptualization of sustainability worked well until the end of the 20th century. Around this period of time, this type of approach became insufficient for two reasons. First, the assumed almost infinite capacity of the environment as a source of inputs and as a sink for waste was refuted by the reality. Thus, the mindset of modern societies changed, and the environment was considered scarce in the above two capacities. To be more specific, it was recognized that the environment had physical limits, and that it would be necessary to optimize this type of scarcity. Second, modern societies started to demand multiple goods and services from the environment and its embedded resources. For some of them there are no markets and, consequently, they have no exchange value or price; however, their optimal provision is essential to the welfare of society.

In order to illustrate the above ideas, let us consider, for instance, the case of forestry systems. Although the sustainability concept in forestry changed between the seventeenth and nineteenth centuries, for this type of system societies nowadays demand not only a long-term stable flow of timber products as were required by the old sustainability, but also an stable provision of basic essential environmental goods and services (e.g., to reduce soil erosion, biodiversity conservation, carbon sequestration, etc.). The explicit consideration of a multiplicity of functions of very different natures underlying the management of the environment and its embedded resources makes the old concept of sustainability clearly insufficient and requiring changes and extensions.

On the other hand, the explicit recognition of the finitude of the environment as well as of the multi-functionality issue are not the only reasons justifying a new view of the concept of sustainability and the corresponding changes in the theoretical framework which underpin its efficient management. In fact, democratic societies demand social participation in the acceptance of the different policies related to the different aspects of sustainable environment management. In short, this crucial issue should be dealt with from the perspective of a participatory decision-making process. For an illustrative example of this type of orientation, see the case of the real urban forest planning problem in Sweden [3].

Briefly, it can be stated that any theoretical framework able to accommodate the above concerns and critical issues and, consequently, characterizing the so-called new sustainability, will require, first, to take into consideration in quantifiable terms the multiplicity of functions associated nowadays with the environment, and, second, to incorporate into it, in one way or another, the manner in which different segments of society or the stakeholders perceive the relative importance of these functions.

A possible first step towards facing up to the above challenges and to correctly performing a sustainable management of the environment and its embedded resources would consist of resorting to the so called "indicator approach" $[4,5]$. According to this approach, the sustainability of a system is characterized by a battery of indicators of different natures. In many instances, these indicators are grouped into three pillars of an economic, environmental and social nature, respectively. Once the indicators and pillars have been defined, the next step consists of an aggregation process of the indicators in order to obtain a final composite index whose value is considered to be a proxy of the degree of sustainability of the system studied.

With this orientation in mind, a crucial task will be to establish a sound and pragmatic procedure for undertaking the above-mentioned aggregation procedure. In this Special Issue, and supported by recent, extensive literature, it is postulated that the most promising and fertile procedure would be to link the concept of an indicator with that of a criterion as it is used within the multi-criteria decision making (MCDM) theory. In this way, all the concepts and techniques of this well-known and widely used theory could underpin a fertile framework for dealing with the so-called new sustainability. Thus, it is important to recall that the main purpose of the MCDM theory consists of proposing sound 
methods for aggregating criteria (objectives, goals, attributes) in conflict. In this way, compromises among the criteria considered with a clear preferential interpretation are obtained [6,7]. In the last ten years or so, practically all the methods within the MCDM theory, with their particular merits and flaws, have been applied for solving different problems associated with sustainable environment management. This issue has been illustrated in some critical reviews [8]. These embryonic ideas would seem to be a promising outline for building a theoretically sound and computationally efficient framework for addressing these types of problems.

In keeping with these ideas, this Special Issue of Sustainability aims to take a step in the direction of linking the conceptualization and measurement of the degree of sustainability of a natural system with the MCDM theory. Thus, we present a collection of ten papers dealing with recent theoretical and applied issues of the so-called new sustainability within the MCDM framework. We hope that this material will reinforce this type of orientation.

The origin of this volume was a kind invitation made by the Editors of Sustainability to organize a Special Issue with this orientation. A call for papers was announced, calling for submissions dealing with theoretical as well as applied aspects of sustainability, understood as a multi-criteria concepts. After a thorough blind review process, ten papers were finally accepted.

As is well known, characterizing and measuring the sustainability of a specific natural system has been the focus of research in many scientific fields, in many cases by resorting to several multi-criteria decision making approaches. This pluridisciplinary perspective is present in the ten papers which form this Special Issue. We have ordered the papers into five blocks according to the area of application. The first block is devoted to the energy planning area and comprises two papers. The first one, by Papapostolou et al. [9], deals with problems related with the potential decarbonisation of the countries forming the European Union. In this way, several alternatives are evaluated by resorting to the Preference Ranking Organisation Method for Enrichment Evaluation (PROMETHEE) method within a fuzzy context. The second paper in this block, by dos Santos Martin et al. [10], deals with the determination of the optimal combination of wind and thermal energy units. The authors apply a hybrid approach combining goal programming with the progressive bound constraint method.

The second block comprises two papers dedicated to agricultural issues. Thus, Segura et al. [11] deal with the problem of sustainability for a supplier evaluation within a food supply chain management perspective. The authors resort to Multi-Attribute Utility Theory (MAUT) and PROMETHEE methods. The other paper in this block, by Gómez-Limón et al. [12], proposes a new composite indicator for measuring environmental sustainability at the farm level by resorting, with a comparative purpose, to three different weighting methods.

The third block comprises papers devoted to the analysis of different issues related with the sustainable management of the environment and its embedded resources. Thus, Ezquerro at al. [13] deal with a sustainable forest management problem in a Spanish forest. The authors propose a lexicographic goal-programming model with two priority levels grouping six goals of economic as well as environmental nature. Barinaga-Rementeria and Etxano [14] address the debate regarding weak versus strong sustainability in the field of rural land use planning. The authors deal with a specific case study in the Basque Country (Spain), implementing a social multi-criteria evaluation by resorting to an outranking orientation.

The fourth block groups two papers that explore the measurement of sustainability at the aggregate level of the countries forming the European Union. In the paper by Garcia-Bernabeu et al. [15], a circular economy composite index is proposed, in order to benchmark the European Union countries' performance. To achieve this purpose, the authors resort to the Technique for Order Preferences by Similarity to Ideal Solutions (TOPSIS) methodology. In the second paper of this block, Stanujkic et al. [16] provide a ranking of these European countries, adopting the Sustainable Development Goals considered in the "Agenda 2030". The authors combine compromise multi-criteria distance function models with Shannon entropy methods. 
The last block comprises two papers combining case studies for dealing with different environmental issues. Thus, André et al. [17] address a problem related to the adoption of an environmental certification in Costa Rica. To achieve this purpose, the authors resort to the Analytic Hierarchy Process (AHP) approach. Finally, Babalola [18] addresses the problem of the sustainable management of home biodegradable waste. In this way, the author presents a case study in Japan, defining and ranking different lines of treatment of the waste by resorting again to the AHP approach.

It is important to remark upon the ample variety of MCDM techniques employed in dealing with the problems analysed in all the papers. Thus, the reader can find applications using PROMETHEE, several variants of goal programming, MAUT, TOPSIS, Combined Compromise Solutions, etc. The very different nature and great social interest in the sustainable problems presented are also remarkable. At any rate, we hope that this material will encourage academic and practitioners to orientate their future research towards this hot and vital topic.

Finally, we would like to thank all the authors for their patience and friendly cooperation throughout the review process. Special gratitude is due to all the referees for their invaluable help. Last but not least, we want to acknowledge the continuous technical support of Ms. Jilian Liang from MDPI.

Author Contributions: Conceptualization, C.R. L.D.-B. and J.G.-P.; methodology, C.R., L.D.-B. and J.G.-P.; investigation, C.R. L.D.-B. an J.G.-P.; writing-original draft preparation, C.R., L.D.-B. and J.G.-P.; writing-review and editing, C.R. and L.D.-B.; supervision, C.R. L.D.-B., and J.G.-P. All authors have read and agree to the published version of the manuscript.

Funding: The financial support of Universidad Politécnica de Madrid under its "Programa Propio" is acknowledged.

Acknowledgments: We are grateful to the members of the Research Group: "Economics for a Sustainable Environment" for their continuous discussion about the concept of sustainability and its linkage with the multi-criteria decision making theory. Thanks are also given to Diana Badder for editing the English.

Conflicts of Interest: The authors declare no conflict of interest.

\section{References}

1. Von Carlowitz, H.C. Sylvicultura Oeconomica Oder Haußwirthliche Nachricht und Naturgemäßige Anweisung zur Wilden Baum-Zucht; Johann Friedrich Braun (2 Bände): Leipzig, Germany, 1713.

2. Fisher, A.C. Resource and Environmental Economics; Cambridge University Press: New York, NY, USA, 1984.

3. Nordström, E.M.; Romero, C.; Eriksson, L.O.; Öhman, K. Aggregation of preferences in participatory forest planning with multiple criteria: An application to the urban forest in Lycksele, Sweden. Can. J. For. Res. 2009, 39, 1979-1992. [CrossRef]

4. Rennings, K.; Wiggering, H. Steps towards indicators of sustainable development linking economic and and ecological concepts. Ecol. Econ. 1997, 20, 25-36. [CrossRef]

5. Pannell, D.J.; Glenn, N.A. A framework for the economic evaluation and selection of sustainability indicators in agriculture. Ecol. Econ. 2000, 33, 135-149. [CrossRef]

6. Diaz-Balteiro, L.; Romero, C. In search of a natural systems sustainability index. Ecol. Econ. 2004, 49, 401-405. [CrossRef]

7. Diaz-Balteiro, L.; Romero, C. Sustainability of forest management plans: A discrete goal programming approach. J. Environ. Manag. 2004, 71, 349-357. [CrossRef] [PubMed]

8. Diaz-Balteiro, L.; González-Pachón, J.; Romero, C. Measuring systems sustainability with multi-criteria methods: A critical review. Eur. J. Oper. Res. 2017, 258, 607-616. [CrossRef]

9. Papapostolou, A.; Karakosta, C.; Kourti, K.; Doukas, H.; Psarras, J. Supporting Europe's Energy Policy Towards a Decarbonised Energy System: A Comparative Assessment. Sustainability 2019, 11, 4010. [CrossRef]

10. Martins, A.; Balbo, A.; Jones, D.; Nepomuceno, L.; Soler, E.; Baptista, E. A Hybrid Multi-Criteria Methodology for Solving the Sustainable Dispatch Problem. Sustainability 2020, 12, 6780. [CrossRef]

11. Segura, M.; Maroto, C.; Segura, B. Quantifying the Sustainability of Products and Suppliers in Food Distribution Companies. Sustainability 2019, 11, 5875. [CrossRef] 
12. Gómez-Limón, J.; Arriaza, M.; Guerrero-Baena, M. Building a Composite Indicator to Measure Environmental Sustainability Using Alternative Weighting Methods. Sustainability 2020, 12, 4398. [CrossRef]

13. Ezquerro, M.; Pardos, M.; Diaz-Balteiro, L. Sustainability in Forest Management Revisited Using Multi-Criteria Decision-Making Techniques. Sustainability 2019, 11, 3645. [CrossRef]

14. Barinaga-Rementeria, I.; Etxano, I. Weak or Strong Sustainability in Rural Land Use Planning? Assessing Two Case Studies through Multi-Criteria Analysis. Sustainability 2020, 12, 2422. [CrossRef]

15. Garcia-Bernabeu, A.; Hilario-Caballero, A.; Pla-Santamaria, D.; Salas-Molina, F. A Process Oriented MCDM Approach to Construct a Circular Economy Composite Index. Sustainability 2020, 12, 618. [CrossRef]

16. Stanujkic, D.; Popovic, G.; Zavadskas, E.; Karabasevic, D.; Binkyte-Veliene, A. Assessment of Progress towards Achieving Sustainable Development Goals of the "Agenda 2030" by Using the CoCoSo and the Shannon Entropy Methods: The Case of the EU Countries. Sustainability 2020, 12, 5717. [CrossRef]

17. André, F.; Valenciano-Salazar, J. Becoming Carbon Neutral in Costa Rica to Be More Sustainable: An AHP Approach. Sustainability 2020, 12, 737. [CrossRef]

18. Babalola, M. A Benefit-Cost Analysis of Food and Biodegradable Waste Treatment Alternatives: The Case of Oita City, Japan. Sustainability 2020, 12, 1916. [CrossRef]

(C) 2020 by the authors. Licensee MDPI, Basel, Switzerland. This article is an open access article distributed under the terms and conditions of the Creative Commons Attribution (CC BY) license (http://creativecommons.org/licenses/by/4.0/). 